\title{
LETTER TO THE EDITOR \\ The Case for Therapeutic Massage as an Adjuvant in Hospitalized COVID-19 Patients
}

Assem Al Refaei

Faculty of Medicine, University of Jordan, Amman 17942, Jordan

"The good physician treats the disease; the great physician treats the patient who has the disease."

\section{- Sir William Osler}

Massage therapy is one of the most popular complementary and integrative medicine (CIM) therapies, in which the manipulation of soft tissue alleviates muscular aches and pains, improves sleep, and promotes mental wellbeing.(1) Massage therapy significantly affects general wellbeing, and has been shown to have beneficial effects in many diseases, including autism, pain syndromes, hypertension, and autoimmune disorders. (2)

According to a recent systematic review, the utility of massage therapy in adult intensive care unit patients improved vital signs and reduced pain and anxiety. (3) The latter, along with other psychiatric disturbances, exhibited an increase during COVID-19 pandemic. (4) For instance, Zhao et al.(5) observed an increase in the Chinese general public anxiety levels during COVID-19 pandemic when compared with previous studies. Measured for by the Hospital Anxiety and Depression Scale (HADS), anxiety was significantly higher among hospitalized COVID-19 patients who eventually died, when compared to survivors. ${ }^{(6)}$ Anxiety levels in these patients were correlated with cortisol levels, the body's stress hormone, which, for its part, was associated with higher mortality among COVID-19 patients. ${ }^{(6,7)}$ In fact, there's a $42 \%$ increase in the hazard of mortality in COVID-19 patients with doubled cortisol concentrations. (7)

The primary mechanism by which cortisol exerts the aforementioned outcomes is at the heart of its immunoregulatory functions, which include altered neutrophil, macrophage, and dendritic cell functions along with impaired lymphocyte egress, natural killer cell cytotoxicity, and induction of apoptosis in lymphocytes. ${ }^{(8-10)}$ The majority of these changes directly and indirectly impair the initiation and progression of an adaptive immune response, the response that eventually clears severe infections and confers long-term protection through memory cell maturation and antibody production. (9) This is evident in the cortisol-correlated reduction in influenza-specific IgG antibodies, upon influenza vaccination in chronically stressed dementia caregivers. (11) Furthermore, a 2009 meta-analysis revealed inadequate antibody responses to influenza vaccine among 59\% of stressed individuals versus $41 \%$ of less-stressed individuals. (12)

Herein lies the case for massage therapy as a complementary piece in COVID-19 management, as it could reduce cortisol levels and thus reduce its accompanied immunological disturbances and improve clinical outcomes.(13) In support of this hypothesis is a study by Loft et al., (14) in which a 4-week massage intervention improved antibody responses to hepatitis $B$ vaccine in students in an academic examinations period. Massage therapy also reduced cortisol, and improved natural killer cells numbers and functions in HIV patients. ${ }^{(15)}$ Furthermore, massage therapy reduced the nuclear accumulation of the inflammatory transcription factor, NF- $\kappa B$ in exercise-induced muscle injury biopsies. Massage therapy also benefited massaged muscles by reducing cellular infiltration, enhancing the anti-inflammatory polarization of macrophages, and potentiating anti-oxidant transcription factor, PGC-1 $\alpha$ signaling, which in turn increases the capacity to counteract oxidative stress. $(16,17)$ This effect may partly attenuate COVID19-related systemic inflammation, which involves vicious loops that eventually lead to cytokine storms and oxidative stressmediated complications. ${ }^{(18-20)}$

Altogether, the author hypothesizes that massage therapy may aid in improving 
patients' well-being-alleviating pain, reducing stress hormone levels, systemic inflammation, and oxidative stress-and, eventually, clinical outcomes. However, given the risk of infection and potential health implications to therapists, the author doesn't suggest practice, but suggests further research to determine the efficacy and safety of massage therapy practice as an early-course adjuvant in hospitalized COVID-19 patients.

\section{COPYRIGHT}

Published under the CreativeCommons Attribution-NonCommercial-NoDerivs 3.0 License.

\section{REFERENCES}

1. Moyer CA, Rounds J, Hannum JW. A meta-analysis of massage therapy research. Psychol Bull. 2004;130(1):3-18.

2. Field T. Massage therapy research review. Complement Ther Clin Pract. 2016;24:19-31.

3. Jagan S, Park T, Papathanassoglou E. Effects of massage on outcomes of adult intensive care unit patients: a systematic review. Nurs Crit Care. 2019;24(6):414-429.

4. Haleem A, Javaid M, Vaishya R. Effects of COVID-19 pandemic in daily life. Curr Med Res Pract. 2020;10(2):78-79.

5. Zhao H, He X, Fan G, Li L, Huang Q, Qiu Q, et al. COVID-19 infection outbreak increases anxiety level of general public in China: involved mechanisms and influencing factors. J Affect Disorders. 2020;276:446-452.

6. Ramezani M, Simani L, Karimialavijeh E, Rezaei O, Hajiesmaeili M, Pakdaman $\mathrm{H}$. The role of anxiety and cortisol in outcomes of patients with Covid-19. Basic Clin Neurosci J. 2020;11(2):179-184.

7. Tan T, Khoo B, Mills EG, Phylactou M, Patel B, Eng PC, et al. Association between high serum total cortisol concentrations and mortality from COVID-19. Lancet Diabetes Endocrinol. 2020;8(8):659-660.

8. Schmidt S, Rainer J, Ploner C, Presul E, Riml S, Kofler R. Glucocorticoid-induced apoptosis and glucocorticoid resistance: molecular mechanisms and clinical relevance. Cell Death Differ. 2004;11(1): S45-S55.
9. Morey JN, Boggero IA, Scott AB, Segerstrom SC. Current directions in stress and human immune function. Curr Opin Psychol. 2015;5:13-17.

10. Priyadarshini S, Aich P. Effects of psychological stress on innate immunity and metabolism in humans: a systematic analysis. Plos One. 2012;7(9):e43232.

11. Vedhara K, Cox NK, Wilcock GK, Perks P, Hunt M, Anderson $\mathrm{S}$, et al. Chronic stress in elderly carers of dementia patients and antibody response to influenza vaccination. Lancet. 1999;353(9153):627-631.

12. Pedersen AF, Zachariae R, Bovbjerg DH. Psychological stress and antibody response to influenza vaccination: a meta-analysis. Brain Behav Immun. 2009;23(4):427-433.

13. Field T, Hernandez-Reif M, Diego M, Schanberg S, Kuhn C. Cortisol decreases and serotonin and dopamine increase following massage therapy. Int J Neurosci. 2005;115(10):1397-1413.

14. Loft P, Petrie KJ, Booth RJ, Thomas MG, Robinson $E$, Vedhara K. Effects of massage on antibody responses after hepatitis B vaccination. Psychosomatic Med. 2012;74(9):982-987.

15. Ironson G, Field T, Scafidi F, Hashimoto M, Kumar M, Kumar A, et al. Massage therapy is associated with enhancement of the immune system's cytotoxic capacity. Int J Neurosci. 1996;84(1-4):205-217.

16. Crane JD, Ogborn DI, Cupido C, Melov S, Hubbard A, Bourgeois JM, et al. Massage therapy attenuates inflammatory signaling after exercise-induced muscle damage. Sci Trans/ Med. 2012;4(119):119ra113.

17. Rius-Pérez S, Torres-Cuevas I, Millán I, Ortega ÁL, Pérez S. PGC-1 $\alpha$, Inflammation, and oxidative stress: an integrative view in metabolism. Oxidat Med Cell Longev. 2020;2020:Article Number 1452696.

18. Bakadia BM, Boni BOO, Ahmed AAQ, Yang G. The impact of oxidative stress damage induced by the environmental stressors on COVID-19. Life Sci. 2020;2020:118653.

19. Laforge M, Elbim C, Frère C, Hémadi M, Massaad C, Nuss P, et al. Tissue damage from neutrophilinduced oxidative stress in COVID-19. Nature Rev Immunol. 2020;20(9):515-516.

20. Mulchandani R, Lyngdoh T, Kakkar AK. Deciphering the COVID-19 cytokine storm: systematic review and meta-analysis. Eur J Clin Invest. 2020;14:e13429.

Corresponding author: Assem Al Refaei, Faculty of Medicine, University of Jordan, Amman 11942, Jordan

E-mail: assem12963@gmail.com 